ESSAY REVIEW

\title{
Technology: society's missing mass
}

Arie Rip discusses Shaping Technology/Building Society, edited by Wiebe E. Bijker and John Law

Don't read this book from the beginning to the end, as I did. Start with Chapter 8, with its intriguing title: 'Where Are the Missing Masses? The Sociology of a Few Mundane Artifacts'. As always, Bruno Latour, its author, is out to entertain and to instruct. And he shifts you into new frames of mind and meaning, where you can't look at a door any more without realizing what a miracle of technology it is, and what it tells us about technology and ourselves.

Walls are a nice invention, but if there were no holes in them there would be no way to get in or out-they would be mausoleums or tombs. The problem is that if you make holes in the walls, anything and anyone can get in and out (cows, visitors, dust, rats, noise (. . ) and, worst of all [to the French], cold (. . .)). So architects invented this hybrid: a wall hole, often called a door (. . .). The cleverness of the invention hinges upon the hinge-pin: instead of driving a hole through walls with a sledgehammer or a pick, you simply gently push the door (. . .); furthermore-and here is the real trick-once you have passed through the door, you do not have to find trowel and cement to rebuild the wall you have just destroyed: you simply push the door gently back (. . ). (p. 227-228)

By having a door, and using it according to its script,' we are relieved of an enormous amount of effort. The work of handling the wall, and the cold draughts, and the keeping out of unwanted visitors, has been delegated to (in this case) a non-human character. It is a reversal of forces: instead of expending efforts directly, tasks are delegated, and the main effort is now in policing the delegates (this is the phrase used by the editors, Bijker and Law, to generalize the point). In this case, policing entails oiling the hinges, making sure the door fits the wall hole, and making sure it is actually being closed after it has been opened.

For this last issue, one has to rely on humans, who are notoriously unreliable. So what can we do?

This is where the age-old Mumfordian choice is offered to you: either to discipline the people or to substitute for the unreliable people another delegated human character whose only function is to open and close the door. This is called a groom or a porter (. . .), or a gatekeeper, or a janitor, or a concierge, or a turnkey, or a jailer. The advantage is that you now have to discipline only one human and may safely leave the others to their erratic behaviour. (p.230) 
But the groom or the porter has to be paid, and overseen, and his work has to be continually checked. So in contrast to the door with well-oiled hinges, the delegation does not really produce a reversal of forces. But there is another choice: to delegate to a non-human, and develop a door-closer or (in French) valet. Once disciplined in terms of its technical configuration, it will work without too much overseeing. Human users will have to adapt, though: sometimes the spring mechanism is too powerful, and the door is slammed shut while you are still passing through. Or with these nice hydraulic door-closers, the initial force necessary to open the door becomes too large for small children and old people.

So does technology, if well embedded, thus solve the problem of delegation and policing undisciplined humans? Yes: that is the reversal of forces, the characteristic promise of technology. No: because non-human characters are never fully reliable either. Latour's story started, in fact, with a note on the door of an institute in the northern suburbs of Paris, which said: 'The Valet Is on Strike! For God's Sake, Keep The Door Closed!' (p.227).

In order to understand technology, how it works, why it works, and also why it sometimes does not work, the notions of delegation and policing are important, because they capture both the technical (configurations that have a particular function, the maintenance of the technical system) and the social (task divisions, and disciplining of humans). Indeed, the whole distinction between the technical and the social becomes superfluous; phrases like 'social shaping of technology' may then limit, rather than enhance, our understanding of the dynamics.

The editors of the book emphasize this point in general terms, and position themselves as speaking for a movement (or perhaps a sect, where members are committed to a particular view):

The contributors to this volume share a commitment to the heterogeneity of social and technical relations. They are also committed to the view that sociotechnical change should be seen as contingent (. . .). (p.201)

The full force of the point becomes apparent if we follow Latour again. He highlights how simple artifacts like door-closers and seatbelts in cars in fact have to cater for different situations and contradictory specifications (e.g. a seat belt must be firm-in case of an accident-and slack-to allow motion in normal circumstances). In other words: '. . . every piece of an artifact becomes fascinating when you see that every wheel and crank is the possible answer to an objection' (p.247)-not only objections about failures to work properly in certain circumstances, as with the seatbelt, but also objections in the sense that intended users may want to escape the disciplining forced on them by the artifact. Hotel room keys have heavy weights attached to them to make it more uncomfortable to carry them around than to hand them back to the hotel manager. This is, of course, a very simple example, but it does show Latour's notion of a 'programme' embedded in the artifact and the work of delegation it has to do, and the 'anti-programme' of undisciplined material reality and the human and social world having other things to do.

If this is so, there are two movements: One, out there, is the alignment of sociotechnical set-ups and the creation of working artifacts, which decrease the number of occasions in which words are used (to delegate). Most of the actions are silent, incorporated (in human or non-human bodies) (p.240). The second movement is that of the analyst: the aim of socio-technical study is to make explicit the polemical process incorporated in a silent artifact, and thus to show the transformations that 
have gone into it ( $\mathrm{p} .258$ and passim).

This is not to weaken the 'hardness' of technology, as some critics of the movement of socio-technical analysis have assumed, and some arguments of members of the movement have, in fact, suggested. As with the 'constructivist' shift in studies of science: "It is not that society and social relations invade the certainty of science or the efficiency of machines. It is that society itself is to be rethought from top to bottom once we add to it the facts and the artifacts that make up large sections of our social ties.' Technology is full of humans, and sociology is full of non-humans (p.254).

From the vantage point that Latour provides, one can read the chapters in the book in a different way. Originally, I expected studies of (socio-)technical change, as the book's subtitle promises, but the authors turn out to focus on what one could call the conditions and circumstances, rather than the changes themselves (in contrast to how Latour started: what is the work of a door, or of artifacts in general?). While it was fascinating reading, I became impatient, because I wanted to get inside the technology as well. In restrospect, however, I could position the cases as studies of the polemical processes that become silent once the artifacts have been created and function 'naturally'.

Law and Callon, with the help of a case study of the development of a British military aircraft, discuss the need for a protected space in which the design work, including the mistakes involved in it, can take place, and how the negotiations can break down and stop the project. Bowker reconstructs a patent battle about electrical logging to explore for oil fields, and shows how the strategies of Schlumberger were geared to creating a breathing space, so that his firm could impose its way of doing things on the practices in oil fields. Bijker shows how a new fluorescent lamp, the 'High-Intensity Daylight Fluorescent Lamp', was designed in the late 1930s in committees trying to resolve a controversy between various lamp manufacturers and with the utilities. Its specifications were such that the hatchets could be buried; what remained was to actually construct it, make it work, and convince customers that they needed the new functions.

In "Constructing "Steel", Misa shows up similar dynamics in the case of the Bessemer-Kelly controversy on the patents for new steelmaking processes in the USA in the 1850 s and 1860 s, and the way a specification of what 'steel' was emerged to accommodate the several parties, including the railway companies which were the big customers. 'Closing the Ranks', by De la Bruhèze, is a fascinating account of how the US Atomic Energy Authority (AEC), its various subgroups and other actors moving in its world, created, during the 1950s and 1960s, a definition of what radioactive waste was, what the problem was and how it might be solved, by way of including some actors and approaches and excluding others. Having closed the ranks, and so protected its space, the AEC world could remain satisfied with the promise of a future solution-only to be surprised, and caught unaware, by the turn of events during the controversy about disposal in salt mines in Kansas in the early 1970s. In Carlson's case study of Edison and his managers inventing the 'kinetoscope' and producing motion pictures for distribution, the problem definition is shown to derive from a production-oriented frame of meaning, and a middle-class bias about the desirable content of motion pictures. This way of creating a protected space turned out to be insufficiently aligned with main customer groups (working class, immigrants) and overall social change. So Edison's venture collapsed.

Although authors and editors try to distance themselves from simple social-shapingof-technology approaches, and add actor strategies, emerging irreversibilities, and 
contingencies, the case studies, with their interest in context and circumstances, fit a social shaping approach perfectly well. Apart from one point: the fact that the battles turn out to be about the shape of future technology.

The issues of promises (and delivery), of expectations and positioning, are recognized, and the editors comment that promises are one of the crucial resources in sociotechnical manoeuvering (p.107), and note how promises of new technologies are used to fix current social relations (p.106). These are comments in passing, however, and the point about future technology is insufficiently analysed. For one thing, promises are not just general offers of a bright future, but entail requirements on the technology to be developed. ${ }^{2}$ The cases of the British military aircraft and the High-Intensity Daylight Fluorescent Lamp illustrate this clearly. Irreversibilities are introduced this way in the development, in which the social and technical cannot yet be distinguished. Thus, a much richer account is possible, in which the non-human characters are allowed in without separating them from the human characters. ${ }^{3}$

There is a second point of constructive criticism to be made about the shaping of future technology, and this is a point which is also relevant to issues of public understanding. I will adapt a distinction introduced by Pinch et al. in their chapter on clinical budgeting techniques in the UK, and argue that there are two 'programmes' in which one can speak about technology (i.e. two repertoires, or registers and their contents). In the 'strong programme', technology is destined to be effective, and claims can and must be made about performance. Technologies and technical artifacts are good when they are functional, fulfil (relevant) needs, and do so efficiently. The 'strong programme' is invoked in debates, in investment decisions, in evaluations, in legitimation discourse, and when presenting technologies to external audiences. The 'weak programme' is more for inside use, although it can be invoked in controversies to show that the work of the other side has not been up to standards. (This is one of the points that Pinch et al. make.) Now, technology is flexible (technically and interpretively), non-linear, contingent. It is not good per se, nor are the functions it will fulfil pre-given. These will be articulated in the course of the development. Technological promises are an integral part of this development.

The 'weak programme', as actors use it, is the one highlighted by those analysts, like the authors and editors of this book, who emphasize the socio-technical nature of technology. I share their commitment to recognizing the importance of the 'weak programme', not just as a repertoire of actors, but also as reflecting something about technology in our world. So attempts toward public understanding of technology should incorporate these insights, and use case materials as presented in this bookeven when this creates the definite risk of recriminations and accusations of 'undermining technology', which will be couched in 'strong programme' terms. ${ }^{4}$

Additionally, however, it is necessary to analyse the role of the 'strong programme', not just polemicize with it. My basic idea (derived from studies of how similar dual repertoires work for science-and, for that matter, in other walks of (professional) life) is that there should be a productive relationship between the two "programmes". In the practice of the actors, there could be better linkages between external declarations and the informal goings-on inside the protected space. In the analysis, it could be through understanding the dynaniics of dual repertoires. Indeed, promises, controversies over design and specifications (and over technical and social infrastructure necessary for the promised technology to materialize), the filling up of requirements, and increasing irreversibility and articulation of what the technology is and can do, are the loci to study the dynamics. 
The book contributes to this study, though less than it would have had it been published more quickly after the workshop and workshop discussions, in 1987, that were its base. It remains a useful collection of interesting case studies, it is well edited and produced, and offers insightful comments by authors and editors. So the library should order it. The chapter by Bruno Latour, though, which is much richer than I could bring out in this review, is a sufficient reason to buy the book yourself.

\section{References}

1 The concept of 'script' is discussed extensively in Akrich's chapter of the book. '. . like a film script, technical objects define a framework of action together with the actors and the space in which they are supposed to act' (p.208). While there may be prescriptions accompanying the object, much of the script is contained in its configuration or technological form. 'To be sure, it may be that no actors will come forward to play the role envisaged by the designer [or put into the object unintentionally, AR]. Or users may define quite different roles of their own. If this happens, the objects remain a chimaera, for it is in the confrontation between technical objects and their users that the latter are rendered real or unreal' (p.208). Akrich presents case material about technical artifacts in developing countries to underscore her conceptual points. Although dense, and often obscure to the general reader, her chapter offers fascinating insights, also for issues of public understanding.

2 I owe this point to Harro Van Lente. See his Promising Technology. The Dynamics of Expectations in Technological Developments (Delft: Eburon, 1993).

3 This is Latour's terminology again. He emphasizes the morality involved, and at two levels: the level of what happens (artifacts may make it impossible for humans to behave badly) and at the level of what should happen (artifacts should be accepted on equal footing as humans):

According to some physicists, there is not enough mass in the universe to balance the accounts that cosmologists make of it. They are looking everywhere for the 'missing mass' that could add up to the nice expected total. It is the same with sociologists. They are constantly looking, somewhat desperately, for social links sturdy enough to tie all of us together or for moral laws that would be inflexible enough to make us behave properly. When adding up social ties, all does not balance. Soft humans and weak moralities are all sociologists can get. The society they try to recompose with bodies and norms constantly crumbles. Something is missing, that should be strongly social and highly moral. Where can they find it? Everywhere, but they too often refuse to see it in spite of much new work in the sociology of artifacts.

I expect sociologists to be much more fortunate than cosmologists, because they will soon discover their missing mass. To balance our accounts of society, we simply have to turn our exclusive attention away from humans and also look at nonhumans. Here they are, the hidden and despised social masses who make up our morality. They knock at the door of sociology, requesting a place in the accounts of society as stubbornly as the human masses did in the nineteenth century. What our ancestors, the founders of sociology, did a century ago to house the human masses in the fabric of social theory, we should do now to find a place in a new social theory for the nonhuman masses that beg us for understanding ( $p .227)$.

4 Similar recriminations were, and are. levelled at analysts and commentators presenting the 'soft' side of science to wider publics, with Alvin M. Weinberg's review article, 'Scientific Choice and the Scientific Muckrakers' (Minerva, 7 (1968/69), 52-63) setting a standard. The 'muckraking' was attributed to Daniel Greenberg, in his The Politics of Pure Science (1967).

Shaping Technology/Building Society, edited by Wiebe E. Bijker and John Law, 1992 (Cambridge, MA: MIT Press), ISBN 026202338 5, viii + 341pp, £26.95 


\section{Author}

Arie Rip is a Professor and Head of Department of Philosophy of Science and Technology at the School of Philosophy and Social Sciences, University of Twente, PO Box 217, 7500 AE Enschede, the Netherlands. 